\title{
Research methods in Engineering Design: A systematic literature review
}

\author{
David Escudero-Mancebo ${ }^{1,2}$ 俞, Nieves Fernández-Villalobos ${ }^{1,3}$, \\ Óscar Martín-Llorente ${ }^{1}$, Alejandra Martínez-Monés ${ }^{2}$
}

\begin{abstract}
The relation between scientific research and industrial design is fraught with controversy. While the number of academic PhD programs on product design grows because the discipline is in its infancy, there is no consolidated method for systematically approaching the generation of knowledge in this domain. This paper aims to review recently published papers from the four top-ranked journals in engineering design in order to analyse the research methods that are frequently used. The research questions consider the aim and contributions of the papers, as well as which experimental design and which sources of data are being used. Frequency tables show the high variety of approaches and aims of the papers, combining both qualitative and quantitative empirical approaches and analytical methods. Most of the papers focus on methodological concerns or on delving into a particular aspect of the design process. Data collection methods are also diverse without a clear relation between the type of method and the objective or strategy of the research. This paper aims to act as a valuable resource for academics, providing definitions related to research methods and referencing examples, and for researchers, shedding light on some of the weaknesses and challenges for current research in the domain of engineering design.
\end{abstract}

Keywords Research methodologies on product design; Engineering design and evaluation

\section{Introduction}

Design as a discipline does not yet have a consolidated research tradition. In 2009, Blessing and Chakrabarti proposed the DRM (Design Research Methodology) motivated by "frustration about the lack of a common terminology, benchmarked research method and a common research methodology in design" (Blessing \& Chakrabarti, 2009, pg 1). However, the term 'design research' does not help to make things clearer, because it is frequently used to refer to approaches and methods for researchers and not for designers (Cash et al., 2016; Creswell \& Creswell, 2017). Herbert A. Simon, in his dissertation about The Science of Design, defined design as a search for an optimum solution in a space of alternatives that take into account the specifications and restrictions of a given problem (Simon, 1996). Design could be considered as a research activity, as it requires information to be gathered and proposals to be evaluated with rigour, resulting in innovative and successful

descuder@infor.uva.es

\footnotetext{
1 Escuela de Ingenierías Industriales

2 Escuela de Ingeniería Informática

${ }^{3}$ Escuela Técnica Superior de Arquitectura

Universidad de Valladolid,

Plaza San Cruz,

47002 Valladolid, Spain
}

products. Nevertheless, to be considered as research, the design activities must generate knowledge.

Since the work of Blessing and Chakrabarti, there have been some relevant proposals that have shed light on the activities designers should carry out in order for their work to be considered as research. Koskinen et al., (2011) proposed the term 'constructive design research' and presented alternatives to integrate research within the practice of design. Rodgers \& Milton (2013) presented a comprehensive catalogue of research methods involved in the design process, pointing out the phases of product design in which they could be applied. Joost et al. (2016) used the term 'design as research' in a volume that compiled discourses of experts about questions on design research and its relationship with other disciplines. Vaughan (2017) presented a survey that collected different points of view related to doctoral education in the opinions of design graduates about practice-based research design. Redström (2017) presented an essay about how to develop theory -knowledge- by practice, experimentation and making -design-. These works are a multi-faceted compendium of practical experiences and visions of experts on how to perform activities related to research in the domain of design. All of them agree on the relevance of this theme due to the increasing number of $\mathrm{PhD}$ programs on design. In this paper, we present an alternative approach to shed light on the relations between research and design: instead of collecting 


\begin{tabular}{|c|c|c|c|c|c|c|c|c|c|c|c|c|c|c|c|c|c|c|c|}
\hline & 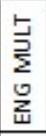 & 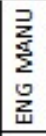 & 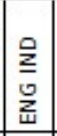 & 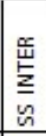 & $\begin{array}{r}\text { IMPACT } \\
\text { FACTOR } \\
(2020) \\
\end{array}$ & $\begin{array}{l}\frac{1}{6} \\
\frac{5}{0} \\
\#\end{array}$ & 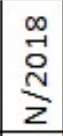 & 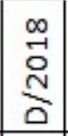 & $\begin{array}{l}\text { の } \\
\stackrel{-}{\circ} \\
\stackrel{N}{7}\end{array}$ & $\begin{array}{l}\sigma \\
\stackrel{\sim}{-} \\
\stackrel{0}{N} \\
\underset{1}{4}\end{array}$ & $\begin{array}{l}\text { I } \\
\text { ○े } \\
\stackrel{N}{2} \\
\sum\end{array}$ & $\begin{array}{l}\sigma \\
\stackrel{1}{0} \\
\stackrel{N}{<}\end{array}$ & $\begin{array}{l}\sigma \\
\stackrel{\sim}{-} \\
\circ \\
\stackrel{N}{\Sigma} \\
\sum\end{array}$ & $\begin{array}{l}\stackrel{\sigma}{1} \\
\stackrel{\circ}{\circ} \\
\end{array}$ & $\begin{array}{l}\sigma \\
\sim \\
\stackrel{\circ}{N} \\
\end{array}$ & 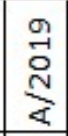 & 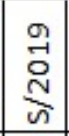 & $\begin{array}{l}\sigma \\
\sim \\
\stackrel{0}{N} \\
0\end{array}$ & $\begin{array}{l}\text { I) } \\
\stackrel{1}{0} \\
\stackrel{N}{2} \\
2\end{array}$ \\
\hline Design Studies & $\mathrm{x}$ & $\mathrm{x}$ & & & 2.780 & $13 / 35$ & $0 / 0$ & $0 / 0$ & $0 / 6$ & $0 / 0$ & $1 / 1$ & $0 / 0$ & $2 / 4$ & $0 / 0$ & $8 / 8$ & $0 / 0$ & $2 / 7$ & $0 / 0$ & $9 / 0$ \\
\hline International Journal of Design & $\mathrm{x}$ & $\mathrm{x}$ & & $\mathrm{x}$ & 1.923 & $13 / 13$ & $0 / 0$ & $8 / 8$ & $0 / 0$ & $0 / 0$ & $0 / 0$ & $4 / 5$ & $0 / 0$ & $0 / 0$ & $0 / 0$ & $0 / 4$ & $0 / 0$ & $0 / 0$ & $0 / 0$ \\
\hline Journal of Engineering Design & $\mathrm{x}$ & & & & 2.588 & $13 / 16$ & $2 / 2$ & $0 / 0$ & $0 / 2$ & $0 / 1$ & $0 / 0$ & $3 / 3$ & $0 / 0$ & $2 / 2$ & $1 / 1$ & $3 / 5$ & $0 / 0$ & $0 / 10$ & $0 / 0$ \\
\hline Research in Engineering Design & $\mathrm{x}$ & $x$ & $\mathrm{x}$ & & 2.655 & $13 / 28$ & $0 / 0$ & $0 / 0$ & $7 / 8$ & $0 / 0$ & $0 / 0$ & $0 / 8$ & $0 / 0$ & $0 / 0$ & $4 / 7$ & $0 / 0$ & $0 / 0$ & $2 / 5$ & $0 / 0$ \\
\hline
\end{tabular}

Table 1 Journals that are the focus of interest in the study. ENG MULT is ENGINEERING, MULTIDISCIPLINARY - SCIE, ENG MANU is ENGINEERING, MANUFACTURING - SCIE, SS INTER is SOCIAL SCIENCES, INTERDISCIPLINARY - SSCI, ENG IND is ENGINEERING, INDUSTRIAL - SCIE. In the cells, A/B figures mean number of reviewed (A) papers versus total number of papers (B). Special issues are underlined.

personal visions of experts, we summarize and classify research papers in terms of methods, approaches and research activities performed by the authors. To this end, we have carried out a systematic review of the literature on research in product design. The overarching research question that drives the review is: What is the current landscape of research methods in product design?

There are many possible ways to analyse, categorize or classify research works because there are many dimensions of analysis. Blessing \& Chakrabarti, (2009) identified the following ones: Paradigm, that includes empiricism (Solomon, 2007) (Randolph, 2003) and ethno-methodology (Atkinson, 1988); aim, research questions and hypotheses; nature of the study, including observational vs interventional (Thiese, 2014), comparative vs non-comparative; methodologies, theories, views and assumptions (Kothari, 2004); units of analysis; data collection methods including recordings, interview, questionnaires (De Leeuw, 2008); role of the researcher (Fink, 2000); time constraints, duration and continuation of the research process; observed processes including layout drawing, prototype or product; setting referring to laboratory or field research (Paluck \& Cialdini, 2014); tasks including type and complexity and nature; number of cases, case size and participants (Diggle et al., 2011); object of analysis distinguishing objects, companies, projects, documents... coding and analysis, analysis and verification methods (Brewer \& Crano, 2000); or findings, that is, statement models or conclusions resulting from the study. In this paper, we aim to identify the main goals pursued by researchers in the field, which research approaches they follow, and which data sources and analytical methods are most (and least) commonly used. Our analysis pivots around the division between empirical qualitative and quantitative research and analytical studies. From this germinal division, data-collection methods, strategies and contributions of the studies are reported in cross-analysis tables. The review points to potential gaps and challenges in the development of this relatively young field of research.

The structure of the document is the following: First, we present the review method and the categories used to classify the papers. We then present the quantitative results of the number of papers in each of the categories and the cross relations of the different classes, shedding light on the relative weight of each of the qualitative and quantitative approaches and the most frequent data-collection methods used. Next, we discuss the usefulness of the obtained results for academics and professionals interested in research design and the paper ends with the conclusions. Complementary material is provided with a brief description of each of the analysed papers.

\section{Method}

We follow Kitchenham (2004) as a guideline for performing the systematic review. The nature of the research question did not suit a usual search in the databases, as we were interested in analysing the approaches to research published in the field of product design. For this reason, we focused on identifying papers published in relevant journals in the field. The data sources are journal papers in the field of industrial design. There are 100 scientific journals indexed in the Journal of Citation Reports 2020 with the term "Design" in its title, relating to different categories from Electronics and Computer Science to Nuclear Physics or Chemistry. We selected Design Studies (DS), the International Journal of Design (IJD), the Journal of Engineering Design (JED) and Research on Engineering Design (RED) as the journals that satisfy the requirement of being in the category denominated as Engineering Multidisciplinary (listed in Table 1). We excluded the International Journal of Technology and Design Education as it focuses on Education, not research. Papers in special issues were excluded to avoid bias in the analysis. We collected 13 papers from each journal, as 13 is the number of papers available in one of the journals under analysis (IJD) and we chose to use the same number of papers per journal to avoid bias in the study. For the journals with more than 13 papers in the period of analysis, random selection was applied.

We focused on the papers published in 2019, which was the most recent available year when this work was started. Every paper was reviewed by at least two of the authors of the 
present work on random assignments. Revisions were done in parallel, and disagreements were resolved in joint meetings. After the round of revisions, the first author of this paper used the data from the analysis to build the final tables and present the results.

The overarching research question posed in this review was: RQ: What is the current landscape of research methods in product and engineering design?

To answer this research question, we focused on three more concrete aspects, with three sub-questions:

RQ1: What are the research goals pursued by the analysed works?

RQ2: What are the main experimental approaches found in the reviewed papers?

RQ3: What data collection methods are employed in the reviewed works?

RQ4: Which instruments are normally used to collect these data?

The following aspects were annotated: aims or contribution of the research, experimental approaches or method, and data collection methods and instruments. Next, we present each of these topics, explaining the respective classification categories used.

\subsection{Aims and contributions}

Concerning the aims/contributions of the research (RQ1), we started from an empty list of categories which was enriched as the number of reviewed papers increased. Finally, the following categories were selected:

To study or propose a methodology which focuses on papers whose main objective is to study an existing design methodology by analysing its validity in works that propose a new design methodology or that develop a part of it more deeply.

To delve into a given aspect of design, which includes papers that focus on exploring an aspect of a design (team communication, sketching, generation of ideas, materials ...) or that explore one area of design which is recognized as challenging (social design, inclusive design, ecological design ...).

To design, develop, or test a specific product, which includes those papers that set out the process of creation or development of a specific product or a group of them. Some of these works describe the overall process of creating a product, and others focus on a specific phase of its development (research, ideation, testing and validation).

To make recommendations or propose guidelines, which include articles whose main aim is to systematize the results of their research in order to provide advice, either at a methodological level or in the design of new products.
Proposing a theory includes those articles that use logical reasoning or mental operations, such as imagination, intuition, abstraction, and deduction, with the aim of enunciating concepts or creating models, explanations or theories about the phenomena under study.

Proposing a framework of analysis or a taxonomy that permits concepts or objects to be classified into categories.

Papers could be labelled in more than one category. This could be the case of a paper that aims to develop a specific product and ends by proposing guidelines.

\subsection{Research approach}

Concerning the experimental design, we propose the use of the classical distinction between quantitative, qualitative and mixed research, following Creswell (2009). To complement this classification, we have also considered the analytical research method, as specified by (Adrion, 1993) cited in (Glass, 1995).

Quantitative empirical studies are those in which a set of numeric values are obtained to analyse the topic of interest (Cash et al., 2016).

Qualitative empirical studies are those in which the focus is not on numerical data, but on exploratory research to understand the topic of interest in depth.

Mixed-methods studies are those that combine both quantitative and qualitative approaches.

Analytical studies are those that use an analytical research method, propose a formal theory or set of axioms, develop a theory, derive results, and, if possible, compare these results with empirical observations.

With respect to quantitative empirical studies, we subcategorize them into experiments, quasi-experiments and non-experiments, depending on the subjects of interest of the experimental group with those of an equivalent control group:

Experiments: by carrying out a random selection of subjects.

Quasi-experiments: with less control of the selection of subjects.

Non-experiments: with similar but not equivalent experimental and control groups.

When a known qualitative strategy of inquiry is used, it is also annotated. According to the definition proposed by Creswell (2009), strategies of inquiry are types of methods, designs or models that provide specific direction for procedures in a research design.

Ethnographic studies are field-oriented studies where the researcher stays on site for a considerable amount of time to analyse practices and behaviours of groups, by observing, interviewing and (sometimes) participating in the process under analysis. Very popular in social sciences, it is also used in architecture and design (Cranz, 2016). 
In phenomenological research, the researcher identifies the essence of human experiences about a phenomenon as described by participants, while the researcher sets aside his or her own perspective (Wilson, 2015).

Grounded theory is a strategy of inquiry in which the researcher derives a general theory grounded in the views of participants, involving the use of multiple stages of data collection (Jørgensen, 2001).

Hermeneutics inquiry focuses on disclosing how participants' interpretations of a phenomenon determine the way they live in the world (Stigliano, 1989). This technique is popular in design and architecture (PerezGomez, 1999).

Case study research is an empirical strategy of inquiry that investigates a contemporary phenomenon within its reallife context, especially when the boundaries between phenomenon and context are not clearly evident (Yin, 2003). In case studies, single individuals, groups, programmes, activity, processes, or events are analysed in depth with the goal of explaining or describing them.

Action research is an approach to introduce a change through cycles of understanding and change with the involvement of the stakeholders. Very popular in social sciences (Clark et al., 2020; Stringer, 2008), it is also proposed for architecture and design (Herr, 2015; Swann, 2002). This method has been included as part of researchthrough-design, practice-based-design research or research-by-design proposals, as previously done by other authors (Kennedy-Clark, 2013; Motta-Filho, 2021), but we prefer to include it as a new perspective.

Practice-based design research and research-through or by design have recently been presented as alternative approaches to generate knowledge by designers and practitioners of product design (Redström, 2017; Vaughan, 2017). Starting from Herbert Read's book, Education through Art (1948), in 1993 Christopher Frayling established three categories with the intention of systematizing research related to art and design: research for art and design, research into art and design, and research through art and design (Frayling, 1994). Findeli et al. (2008), aiming to conceptually and methodologically clarify the concepts, referring specifically to design, delved into the for-about-through model, which, as stated by (Herrera Batista, 2010), has been gaining popularity in recent years within the academic community. Research for design is normally carried out for the development of a design project, and the final product, therefore, is an object or artifact. This research does not have a scientific purpose and is often not intended to be published or discussed, but rather uses tacit knowledge. Its main objective is to ensure that the different conditioning factors of design (aesthetical, psychological, ergonomic, technological, etc.) have been considered appropriately in the design process. Research about design or research into design is one in which design is taken as a research subject. It is normally carried out from other disciplines that are not properly design, such as anthropology, history, psychology, semiotics, etc. It usually deals with the design of its objects, processes, actors, meaning and importance for society, business, culture, etc. In this approach, therefore, we find a clear separation between design practice and design research (Findeli et al., 2008). Finally, Research through design, or research by design, "focuses on the role of a product prototype as a research instrument" - (Keyson \& Bruns, 2009) cited by (Findeli et al., 2008) - . In this approach, the subject and object of the investigation is the design itself. Therefore, it can be understood as an integration of research for design and research about design, taking the interest in improving the practice of design from the first, and the methodological rigor that can be carried out from other disciplines from the second (Findeli et al., 2008).

Case study is generally used for exploratory research or for pre-testing some research hypotheses (Blessing \& Chakrabarti, 2009). Action research requires a high degree of flexibility and is usually qualitative, data driven, participatory, and makes use of multiple data sources. Case study and action research also appear in the following criteria of classification, following the proposal of (Blessing \& Chakrabarti, 2009) referring to data-collection techniques.

\subsection{Data-collection techniques}

In this subsection, we present the list of data-collection techniques we have annotated. We follow the classification proposed by (Blessing \& Chakrabarti, 2009), excluding experiments, case study and action research that we prefer to include in the list of inquiry research strategies presented in the previous subsection.

Observation is a technique in which the researcher records, in real time, what is happening, either by hand, recording it or using measuring equipment. As (Blessing \& Chakrabarti, 2009) explain: 'The quality of observational data is highly dependent on the skill, training and competency of the observer' (Blessing and Chakrabarti 2009: 257). Observations are the main source of data in ethnographic studies (see section 2.1), but this strategy is also commonly used in social sciences (Creswell, 2009) and in visual design (Goodwin, 2000), architecture (Cuff, 1992) and design (Wasson, 2000).

Simultaneous verbalization refers to the situation in which the participants speak aloud while using a system, with the aim of providing information about the cognitive behaviour of the participants, which may not be obtained through normal observation. Often used to analyse problem-solving behaviour, its most important feature is the real-time aspect. Simultaneous verbalization sessions usually last a few hours and never more than a day, due to the effort required by both the participants and the 
researchers in their corresponding analysis. Although audio recordings are sometimes used to record simultaneous verbalization, they are understood as inappropriate for a process such as design, which usually involves drawings and gestures, so video recordings are considered more appropriate.

Collecting technical documents consists of obtaining technical documents related to a particular project, topic or product, from various sources. Analysis of these documents is often used early in a research project in order to understand the organisation, the background of the project and the experience of the designers. It is commonly employed in most observational studies. However, if it is used as a single source of information, it can result in such limitations as the usual lack of data on the context in which the documents were created, and the reason for their content. It is, therefore, convenient to complement them with other methods such as interviews.

Collecting physical objects involves mock-ups, prototypes and other physical models that may be relevant for developing a product or testing it. The model or prototype could refer to a part of the product or the whole product. For traditional engineering research, which focuses, for example, on the analysis of product behaviour, the products are the main source of data (Blessing 2009: 269). In our review, we consider those works that start collecting different objects to carry out a study on their usefulness, or on the behaviour of users, for example. The object is a general term that can refer both to drawings and physical objects. Among the former, we find all those sketches, drawings and diagrams that have emerged throughout the conception of a product or its development, or throughout a research process, which could yield important information to organise ideas and draw conclusions.

Questionnaires are used to collect people's thoughts or opinions about a certain product, process or method. A priori, they seem easier to use than real-time methods, such as observation or simultaneous verbalization, and they are useful to obtain data from a greater number of cases. However, some of its disadvantages, such as the time required by the participants and the potential bias of the results, must also be taken into account.

Interviews have the same purpose as the questionnaires, but are carried out face to face. Sometimes they are not carried out individually, but using a group dynamic known as focus group: a group interview that mixes aspects of interviews and observations, as it provides information from the study of the interactions between participants. Focus groups can provide richer information than interviews, but they can have a negative effect on the contribution of specific participants.

\subsection{Instruments for the collection of data}

Data collection methods are supported by instrumentation. This section describes the categories we found to respond to RQ4. Independently of the strategy of inquiry applied, there are a number of instruments that are used to keep records of the observations. These recordings are important to keep evidence and to enable the reproducibility of the analysis. We annotate the classical audio, video and image recordings and the more recent technique of eye tracking (Bergstrom \& Schall, 2014).

In experiments and case studies, we are also interested in physical measurements that are used to objectify observations.

When questionnaires and/or interviews are the datacollection techniques, we annotate who is the attendee, distinguishing between stakeholders, users of products or participants (observed people) in the research and experts or designers. We also found it relevant to annotate when the study uses workshops as a means to obtain information.

The last topic of interest that has been annotated is the fact that the research work uses simulation algorithms or tools as a source of information. We use this tag when the simulation tools are a fundamental part of the research, as it provides the information analysed (Behera et al., 2019) in the paper, or because the tool or the algorithm itself is the main contribution (Mathias et al., 2019).

\section{Results}

\subsection{Aims and contributions}

Table 2 shows the labels assigned to each of the papers analysed. This section summarises the results related to RQ1. As shown in Table 2, most of the works focus on methodologies or on the analysis of a specific aspect of the design processes. The presentation of a product and the building up of knowledge with taxonomies, guidelines, theories, or reviews, are exceptions.

Three papers propose a theory: (Comi et al., 2019) presents the concept of shared professional vision; (Benavides \& LaraRapp, 2019) presents the principle of weaker dependencies in axiomatic design; and (Martinec et al., 2019) introduces the state-transition model (synthesis, analysis, evaluation) in conceptual design.

Five works focus on the evaluation of a specific product: a software product in (Takahashi et al., 2018) and (Belkadi et al., 2019); or physical objects in the case of (Roesler et al., 2019), (Hyysalo et al., 2019b) and (McKinnon \& Sade, 2019). In the last two cases, the product is involved in a research-through-design process. 
Concerning the works related to methodologies, we find papers that propose a method based on analytical methods or algorithmic solutions such as those related to axiomatic design (B. Chen et al., 2019; R. Chen et al., 2019); those related to such methods as research-through-design, where the importance of the method followed is prominent in the study (Hanrahan et al., 2019; Hyysalo et al., 2019b; McKinnon \& Sade, 2019; Tsai \& Hoven, 2018); or methodologies for product development such as (Daalhuizen et al., 2019), with emphasis on different aspects such as work in groups (Gyory et al., 2019) or sustainability (Santolaya et al., 2019).

Six papers present frameworks of analysis or classifications with different purposes. (Bresciani, 2019) for classifying visualization dimensions, (McDonald \& Michela, 2019) to classify moral goods, (Roy \& Warren, 2019) for card sets, (Park-Lee \& Person, 2018) identify three practices on briefing, (Vegt et al., 2019) deduce 3 types of invasiveness evoked by the rules in gamified brainstorming, and (Valverde et al., 2019) classify the type of feedback in automotive push buttons.

Proposing recommendations is a common result in the analysed research papers, including a variety of themes such as: recommendations on the use of guidelines by new designers (Reimlinger et al., 2019); the use of specific materials (Genç et al., 2018; Pedgley et al., 2018); how to orient future studies on the use of mobile technology by elderly people (Q. Li \& Luximon, 2018), or about design and poverty (Jagtap, 2019) or ethnographic studies in developing countries (Wood \& Mattson, 2019); appliance design (Selvefors et al., 2018); use of games in brainstorming (Vegt et al., 2019); or specifying requirements (Morkos et al., 2019).

The most frequent type of works delve into a particular aspect of product design such as sketching (Self, 2019; Sung et al., 2019), prototyping (Mathias et al., 2019), material (Aktas \& Mäkelä, 2019; Barati et al., 2019; Pedgley et al., 2018), interaction (Hobye \& Fagerberg Ranten, 2019; Valverde et al., 2019), briefing (Park-Lee \& Person, 2018), working in groups (Graeff et al., 2019), or iterations and testing (Piccolo et al., 2019). 


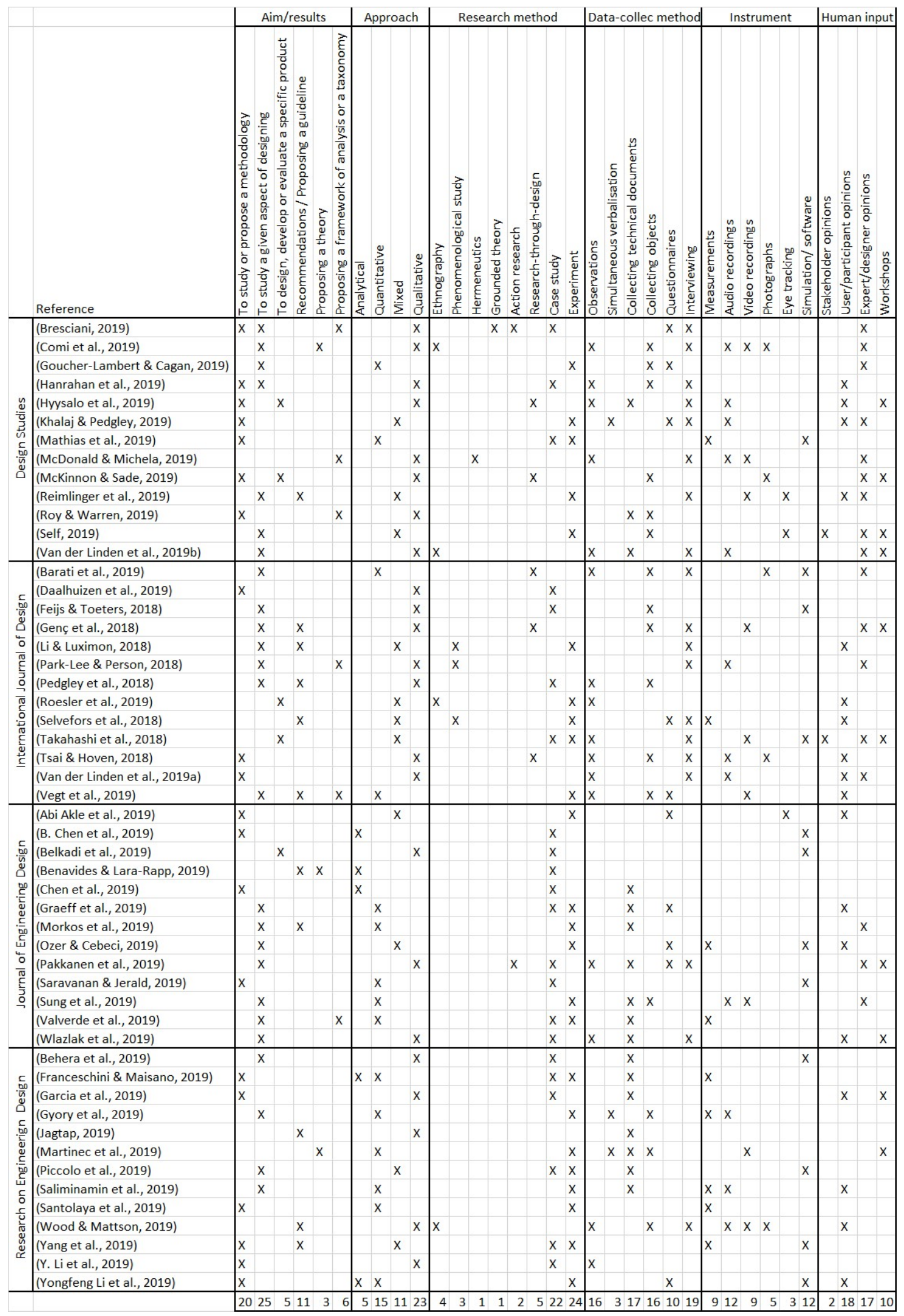

Table 2 Classification of the different papers analysed in the categories of aim/results, approach and research method, data-collection technique, instruments and human based information. The papers are assorted by journal. 


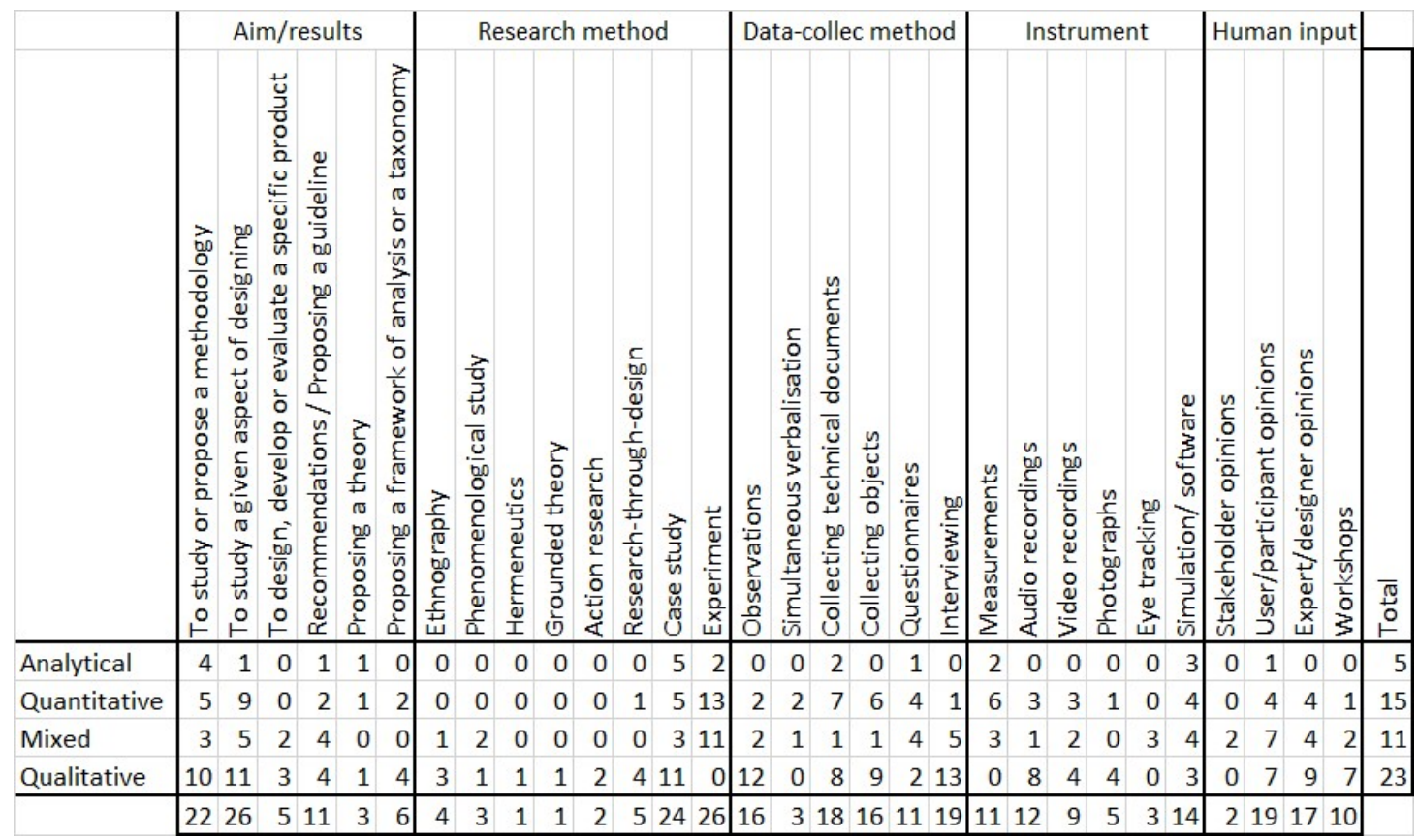

Table 3 Number of works in each (sub)category per research approach

\subsection{Strategies of inquiry and methodologies}

This section summarises the results related to RQ2: qualitative approaches are a majority, but the number of quantitative or mixed-methods studies is also relevant. Other approaches, such as the use of analytical methods, are less frequent. Table 3 shows that, when the goal of the paper is related to proposing or studying a methodology (first column in Table 3), the percentage of pure quantitative papers is lower than in the rest of the cases. Regarding whether there is a tendency towards any methodology depending on the journal; Table 2 shows that the Journal on Engineering Design seems to focus more than the other journals on nonqualitative strategies of inquiry.

When quantitative methods are used, experiments are more frequent than quasi-experiments and non-experiments (13 out of the 15 quantitative studies present an experiment). We found 26 experimental studies, with 5 quasi-experiments (Saliminamin et al., 2019a; Santolaya et al., 2019; Self, 2019; Sung et al., 2019; Vegt et al., 2019) and 4 non-experiments (Morkos et al., 2019; Piccolo et al., 2019; Roesler et al., 2019; Selvefors et al., 2018).

The use of case studies is pervasive in qualitative research (more than half the studies that classified as qualitative base the research on a case study). Furthermore, many quantitative studies support results from case studies; for example, some analytical studies in which case studies are used as proof of concept of the proposed models (R. Chen et al., 2019; Y. Li et al., 2019; Zhang \& Thomson, 2019).
Nevertheless, other qualitative methods, such as ethnography, action research and phenomenological studies, are also used. The use of specific methods related to design is scarce (the discussion about this concern is dealt with in detail below). Ethnography is used in three cases (Comi et al., 2019), (Roesler et al., 2019) and (Van der Linden et al., $2019 \mathrm{~b}$ ) - also the annotation as observation in the tables - and one more paper uses ethnography as the study focus (Wood \& Mattson, 2019).

Action research is used by Pakkanen et al. (2019) to investigate, in combination with case studies, modular systems in industrial environments. The work of (Bresciani, 2019) could be considered an action research study with the goal of building a grounded theory evaluation technique for visual thinking.

McKinnon \& Sade (2019) align their work in the field of research through design using a set of gadgets to obtain information about environmental home good practices. Research through design is also used by (Genç et al., 2018) to explore new materials and (Tsai \& Hoven, 2018) to explore user experience. (Hyysalo et al., 2019a) present the evaluation of a panel following the principles of research through design. Close to this method is that presented by (Barati et al., 2019), who complement their study with workshops where a group of students explores their proposals.

\subsection{Data-collection techniques}

Results regarding RQ3 are summarised in this section. Table 3 shows what the main sources of information are for the 
different types of studies. None of the instruments identified seem to be dominant in the papers studied. Technical documents of a diverse nature are the main source of information used (in 17 out of the 52 papers analysed). Interviewing is also frequent (19 times). Expert and user opinions are both used as sources of information, but neither is a majority (17 and 18 papers, respectively). Observation is mostly used in qualitative studies, where almost half use this technique. Concerning quantitative studies, apart from measurements, expert opinions appear as a frequent resource. This is because it is common to collect the opinions of experts in questionnaires or in evaluation templates that convert opinions into numeric values.

Verbalization is used in (Martinec et al., 2019) and (Gyory et al., 2019) for team work analysis and in (Khalaj \& Pedgley, 2019), where designers and users had to verbalize impressions.

Objects are collected as a data source in a relevant number of studies. Some are the results of students' work as in (Gralla et al., 2019); brainstorming outputs (Vegt et al., 2019); prototypes (Barati et al., 2019; Feijs \& Toeters, 2018a), or commercial products (Roy \& Warren, 2019). Sketches are the type of object analysed in (Comi et al., 2019; Genç et al., 2018; Goucher-Lambert \& Cagan, 2019; Gyory et al., 2019; Martinec et al., 2019); while for (Sung et al., 2019) and (Q. Li \& Luximon, 2018), sketches are the main concern of the research.

Questionnaires are less frequently used, and when this happens, they are designed ad-hoc for each study. No standardized questionnaires have been found in the reviewed works. Questionnaires take different formats: Amazon Mechanical Turk is used once (Goucher-Lambert \& Cagan, 2019); a Likert scale tool evaluation (Graeff et al., 2019); binary and open questions (Pakkanen et al., 2019); ranking of preferences (Franceschini \& Maisano, 2019); or ad-hoc software tools (Y. Li et al., 2019).

Interviews are frequently used as a source of information in qualitative and mixed strategies of inquiry. Interviews are associated with phenomenological studies (Q. Li \& Luximon, 2018; Park-Lee \& Person, 2018; Selvefors et al., 2018) and also in ethnographic studies (Comi et al., 2019; Roesler et al., 2019; Van der Linden et al., 2019a; Wood \& Mattson, 2019). The interviewed population can be a group of users of a given technology (Q. Li \& Luximon, 2018) or a group of experts (Bresciani, 2019).

\subsection{Instruments}

Results regarding RQ4 are summarised in this section. Measurements refer both to metrics obtained with a physical device and to qualitative ratings obtained from human-based scores. In the first group, we can mention the metrics of energetic consumption (Santolaya et al., 2019; Selvefors et al., 2018), mass material (Santolaya et al., 2019), volumes of objects (Mathias et al., 2019), displacement of buttons (Valverde et al., 2019), online shopping user interaction data (Ozer \& Cebeci, 2019), or the timing of tasks in (Mathias et al., 2019). In the second group, we can cite (Gyory et al., 2019; Saliminamin et al., 2019b), which scores the quality of design proposals, and (Franceschini \& Maisano, 2019), who use design preferences as the input for an analytical model.

Simulations and/or software developments of algorithms take on an important role in several papers. (Belkadi et al., 2019) present a software tool; (B. Chen et al., 2019; Feijs \& Toeters, 2018b; Mathias et al., 2019; Takahashi et al., 2018) present or test software tools for different goals, such as analysing Lego buildings, generating fashion patterns for projecting requirements into design parameters etc. (Y. Li et al., 2019) focus on modelling knowledge; (Piccolo et al., 2019) use analysis and visualization tools to present results; while (Ozer \& Cebeci, 2019; Saravanan \& Jerald, 2019) use machine learning techniques such as neural networks and clustering.

Workshops are frequently used for evaluating results and sharing experiences by a group of experts with discussions (McKinnon \& Sade, 2019; Self, 2019; Van der Linden et al., 2019a, 2019b; Wlazlak et al., 2019). In (Genç et al., 2018; Martinec et al., 2019), the workshops become designing activities in the research-through-design methodology. In (Takahashi et al., 2018), workshops are used to observe users while they interact with a system and, in (Pakkanen et al., 2019), to collect information from experts. In (Garcia et al., 2019), workshops are meetings with stakeholders.

The opinions of stakeholders can be the core of the research study (Self, 2019) or they can be used as part of usability tests (Takahashi et al., 2018). Most often, questionnaires and interviews are performed with users of a product (Hanrahan et al., 2019; Ozer \& Cebeci, 2019; Roesler et al., 2019; Selvefors et al., 2018); by active participants of the process under analysis, such as professionals in companies (Reimlinger et al., 2019; Wlazlak et al., 2019); or by students that are required to do a project (Abi Akle et al., 2019; Graeff et al., 2019; Y. Li et al., 2019; Vegt et al., 2019). The experts that participate in questionnaires or interviews are designers architects, engineers (Q. Li \& Luximon, 2018; Pakkanen et al., 2019; Park-Lee \& Person, 2018), or academic staff evaluating results (McKinnon \& Sade, 2019; Morkos et al., 2019; Sung et al., 2019). In interviews occurring in ethnographic studies, the subjects providing information could be considered the topic of analysis (Wood \& Mattson, 2019), but at the same time, they could be experts (Comi et al., 2019). 


\section{Discussion}

\subsection{Variety of aims and approaches}

The principal finding of our research is that there is a very high diversity in the works presented in journals related to industrial design and product development. This variety affects the aims and scopes of the research works, the methods and the data sources. Variety affects the papers in the four journals analysed with only minor differences among them. Thus DS and RED seem to focus more on methodological aspects, while IJD and JED focus more on delving into particular aspects of the design process or on products, but at most 7 papers out of the 13 fall into one of the categories. In principle, a prototypical paper of the DS or of IJS journals would follow a qualitative approach (only 2 papers in each journal are purely quantitative), while most of the papers from JED and RED would follow a quantitative or analytical approach (only 3 and 5 papers, respectively, are purely qualitative). However, we have found papers with both approaches in all the journals. RED uses less self-reported data (interviews, questionnaires or workshops), while DS uses this source of data the most, but in both journals there are exceptions, such as (Mathias et al., 2019) in DS or (Garcia et al., 2019) in RED. Despite this broad spectrum of papers, we found a clear interest in methodologies and the in-depth analysis of a given aspect of the whole process of designing generally applied to a particular case study. The interest in both topics is justified by the nature of the design and the youth of the discipline. As a process of searching for optimum solutions, design is clearly related to methodological concerns. As a young discipline, the number of contributions in the different stages of the whole design process is huge. More surprising and frustrating is the relatively low number of papers proposing recommendations, guidelines, frameworks and taxonomies, because the generation of knowledge in these particular topics is essential for the growth of the discipline.

Another finding of the study is that there is very little space for presenting products resulting from design projects in the reviewed journals. Some of the publications, such as IJD, include a specific section for presenting products (Design Case Studies), but overall, there are very few papers that present the whole design cycle of specific products. In our review, we found only 5 published in the targeted period (2019), and 2 of those refer to software products. We inspected the IJC issues published in the last four years of IJD, and we found only 9 papers out of 46 in the section Case Studies and not all of them were focused on the development of a product. Most product development works are not publishable if they do not generate knowledge; nevertheless, industrial and product design is a domain in which both innovation and evaluation are almost a must for success. We believe there may be a possible lack of interest on the part of design and development teams for publishing in these kinds of journals. This could be the situation, in particular, of design teams working in companies, where research journals are not the main channel for disseminating products and much less for sharing knowledge. This is unfortunate for the growth of industrial design as a discipline, because the sharing of knowledge generated in the industry has permitted other disciplines to advance. Such has been the case of computer science, where large companies have research departments that share knowledge and tools with the community, leading to an undoubted growth in the body of knowledge in the discipline.

In the review, we have observed that research-through-design appears in several works (Barati et al., 2019; Genç et al., 2018; Hyysalo et al., 2019a; McKinnon \& Sade, 2019; Tsai \& Hoven, 2018), but it is far from being the most popular approach. In fact, it shares space in the reviewed journals with antagonistic approaches, such as the analytic methods. This paper shows that research-through-design occupies space in prestigious journals indexed in scientific categories due to its capability for generating knowledge. Nevertheless, the relatively low number of papers that follow this paradigm seems to suggest that curricula and courses on research methodologies in engineering, industrial or product design should not focus exclusively on this approach, presenting the broader umbrella of research methods in engineering design that exist in journal papers in this area. The literature review presented in this paper contributes to this aim, while offering academics and researchers direct access to different approaches to the generation of knowledge in the domain of product design.

\subsection{The human factor on research}

In spite of the analysed publications being indexed in engineering categories of the science classification of the Journal Citation Report, there are many papers with qualitative research. Observations by the authors of papers and/or opinions of experts and users are very frequent sources of information, so experimentation is not a requirement. We understand this is due to the humanistic facet of design, which places this area of knowledge close to the arts and human behaviour related disciplines, but contrasts with other disciplines such as psychology, where human opinions and observations are also relevant, while experimentation (with hypothesis and statistical tests) is almost a must in a scientific publication.

Using experts in evaluations is a common option in user experience evaluation, where the so-called heuristic evaluations are popular as an alternative to using real users, due to their lower cost (Nielsen \& Molich, 1990). Taking decisions supported by expert opinions runs the risk of experts becoming influencers who condition tendencies because of the well-known authority effect (Cialdini, 2009). The role of influencers and tendencies is widely extended in 
product design when producing commercial products. We have not seen this effect in our study, where experts are mainly professors or professionals and do not influence designers or researchers very much.

\subsection{Relation to other surveys}

Probably due to the youth of engineering design and product design as research disciplines, the number of papers devoted to literature reviews in these fields is still sparse. From the few reviews found, most refer to particular aspects of engineering design: such as inspiration and fixation (Crilly, 2019); sustainability (Coskun et al., 2015); user value (Boztepe, 2007); Alzheimer and play experience (Anderiesen et al., 2015); performance in industrial design (Candi \& Gemser, 2010); relation between creativity, functionality, and aesthetics (J. Han et al., 2021); fuzzy front-ends for product development (Park et al., 2021); surrogate models and computational complexity (Alizadeh et al., 2020); smart design (Pessôa \& Becker, 2020); design and poverty (Jagtap, 2019); mass customization (Ferguson et al., 2014); product stigma (Schröppel et al., 2021); uncertainty (X. Han et al., 2020); decision making methods (Renzi et al., 2017); modular product design (Bonvoisin et al., 2016); or productservice systems (Vasantha et al., 2012).

More interesting, for their similarity with respect to the present study, are the works presented in (Tempczyk, 1986) and (Cantamessa, 2003), both presenting reviews or surveys about research and studies on engineering design. These two works and the one presented in this paper differ in their sources of information. (Tempczyk, 1986) made a survey by sending questionnaires to academic staff concerning research subjects and methods; (Cantamessa, 2003) made a review of the proceedings of two editions of the conference on Engineering Design. There is a temporal distance of 17 years between (Tempczyk, 1986) and (Cantamessa, 2003) and 18 years between (Cantamessa, 2003) and the present study, but we must highlight the fact that the three studies report methodologies as one of the main topics of research. Computer aided products are reported in (Tempczyk, 1986) as a relevant topic, and (Cantamessa, 2003) also refers to software tools as a recurrent topic, while we also identified a category named simulation which included software tools and algorithms. The three works also report a high variety of approaches and themes. The main differences between these studies and the present one is that (Tempczyk, 1986) reports on training as an important concern for researchers and (Cantamessa, 2003) observes different streams of research, loosely coupled with an excess of referencing to previous works. As regards references to training concerns, we did not find any paper related to training, probably because, nowadays, there are journals specifically devoted to learning in the domain of engineering and design. As regards the criticism of Cantamessa concerning the notable amount of self-references in the analysed papers, we did not observe such a circumstance in the journal papers we have reviewed. On the contrary, our review has found that the papers reviewed contain complete state-of-the-art sections in which other research groups are referenced and other studies are discussed. This finding partially contradicts what Cantamessa (2003) found in his review. We think that the nature of the sources of data in his review, based on proceedings which are shorter could have influenced these divergent results. Our study may point to a more mature stage of research that builds on the knowledge already offered in the community. This finding may be based on the fact we are working on journal papers that offer more mature results.

\subsection{Limitations}

The systematic literature review presented in this paper covers a recent period of time spanning one year of publications. The sample is representative of recent research on industrial design, but it does not provide information about tendencies in the field. For example, we have observed a relevant number of quantitative studies in comparison to qualitative ones, but we cannot say if this is a tendency. Future work would be required to compare our results with those of a longitudinal study covering a larger period of years. We expect that our work can be considered as a first step in this longer-term study that could provide useful information about the evolution of research into the young discipline of industrial design and product development

\section{Conclusions}

In this paper, we have presented a systematic literature review on research methods and instruments used in a one-year period of research papers in the field of product design. By taking this approach, we offer a "fixed image" of recent research in the area and point to some gaps and challenges for the field.

The review shows that there is no single methodological approach accepted as the standard in the field; and that there is a large variety of goals, approaches, data collection methods and instruments to collect them. In spite of this variety, we have observed a certain preference towards qualitative methods, which can be justified by a strong trend towards the consideration of the human factors in design. We have observed that the most recent approaches to research in design are not prominent in the field. Whether this is due to the relative novelty of these approaches or not is a matter of future research.

We think that this paper contributes in that it is a helpful guide for researchers to have a map of the kind of works that are expected by high impact scientific journals in the domain of engineering design. Academics can find, in this paper, a list of topics (methodologies, data-collection procedures, instruments etc...) that must be part of the programme of courses on research in design. Finally, practitioners and designers should understand that methodologies, evaluation procedures and the resulting guidelines produced after designing a particular product could be of interest for these 
high impact journals as long as they contribute to enriching the body of knowledge in engineering design.

\section{References and appendices}

Abi Akle, A., Yannou, B., \& Minel, S. (2019). Information visualisation for efficient knowledge discovery and informed decision in design by shopping. Journal of Engineering Design, 30(6), 227-253. https://doi.org/10.1080/09544828.2019.1623383

Adrion, W. R. (1993). Research methodology in software engineering. Summary of the Dagstuhl Workshop on Future Directions in Software Engineering " Ed. Tichy, Habermann, and Prechelt, ACM Software Engineering Notes, SIGSoft, 18(1), 36-37.

Aktas, B. M., \& Mäkelä, M. (2019). Negotiation between the Maker and Material: Observations on Material Interactions in Felting Studio. 13(2), 55-67.

Alizadeh, R., Allen, J. K., \& Mistree, F. (2020). Managing computational complexity using surrogate models: a critical review. Research in Engineering Design, 31(3), 275-298.

Anderiesen, H., Scherder, E., Goossens, R., Visch, V., \& Eggermont, L. (2015). Play experiences for people with Alzheimer's disease. International Journal of Design, 9 (2), 2015.

Atkinson, P. (1988). Ethnomethodology: A critical review. Annual Review of Sociology, 14(1), 441-465.

Barati, B., Karana, E., \& Hekkert, P. (2019). Prototyping Materials Experience: Towards a Shared Understanding of Underdeveloped Smart Material Composites. International Journal of Design, 13(2), 21-38.

http://www.ijdesign.org/index.php/IJDesign/article/vie wFile/3255/856

Behera, A. K., McKay, A., Earl, C. F., Chau, H. H., Robinson, M. A., de Pennington, A., \& Hogg, D. C. (2019). Sharing design definitions across product life cycles. Research in Engineering Design, 30(3), 339-361. https://doi.org/10.1007/s00163-018-00306-0

Belkadi, F., Le Duigou, J., Dall'Olio, L., Besombes, G., \& Bernard, A. (2019). Knowledge-based platform for traceability and simulation monitoring applied to design of experiments process: an open source architecture. Journal of Engineering Design, 30(8-9), 311-335. https://doi.org/10.1080/09544828.2019.1642463

Benavides, E. M., \& Lara-Rapp, O. (2019). Ideal output for a robust conceptual design process. Journal of Engineering Design, 30(4-5), 103-154. https://doi.org/10.1080/09544828.2019.1598552

Bergstrom, J. R., \& Schall, A. (2014). Eye tracking in user experience design. Elsevier.

Blessing, L. T. M., \& Chakrabarti, A. (2009). DRM: A design reseach methodology. Springer.

Bonvoisin, J., Halstenberg, F., Buchert, T., \& Stark, R. (2016). A systematic literature review on modular product design. Journal of Engineering Design, 27(7), $488-514$.

https://doi.org/10.1080/09544828.2016.1166482

Boztepe, S. (2007). User value: Competing theories and models. International Journal of Design, 1(2).

Bresciani, S. (2019). Visual design thinking: a collaborative dimensions framework to profile visualisations. Design Studies, 63, 92-124 https://doi.org/10.1016/j.destud.2019.04.001

Brewer, M. B., \& Crano, W. D. (2000). Research design and issues of validity. Handbook of Research Methods in Social and Personality Psychology, 3-16.

Candi, M., \& Gemser, G. (2010). An agenda for research on the relationships between industrial design and performance. International Journal of Design, 4(3).

Cantamessa, M. (2003). An empirical perspective upon design research. Journal of Engineering Design, 14(1), 1-15. https://doi.org/10.1080/0954482031000078126

Cash, P., Stanković, T., \& Štorga, M. (2016). An introduction to experimental design research. In Experimental Design Research (pp. 3-12). Springer.

Chen, B., Hu, J., \& Chen, W. (2019). DRE-based semiautomation of the axiomatic design transformation: from the functional requirement to the design parameter. Journal of Engineering Design, 30(7), 255287. https://doi.org/10.1080/09544828.2019.1627296

Chen, R., Liu, Y., Fan, H., Zhao, J., \& Ye, X. (2019). An integrated approach for automated physical architecture generation and multi-criteria evaluation for complex product design. Journal of Engineering Design, 30(2-3), 63-101. https://doi.org/10.1080/09544828.2018.1563287

Cialdini, R. B. (2009). Influence: Science and practice (Vol. 4). Pearson education Boston, MA.

Clark, J. S., Porath, S., Thiele, J., \& Jobe, M. (2020). Action research. New Prairie Press.

Comi, A., Jaradat, S., \& Whyte, J. (2019). Constructing shared professional vision in design work: The role of visual objects and their material mediation. Design Studies, 64, 90-123. https://doi.org/10.1016/j.destud.2019.06.003

Coskun, A., Zimmerman, J., \& Erbug, C. (2015). Promoting sustainability through behavior change: A review. Design Studies, 41, 183-204. https://doi.org/https://doi.org/10.1016/j.destud.2015.0 8.008

Cranz, G. (2016). Ethnography for designers. Routledge.

Creswell, J. W. (2009). Research Design: Qualitative, Quantitative and Mixed Approaches (3rd Edition). In Research Design: Qualitative, Quantitative, and Mixed Methods Approaches. https://doi.org/10.2307/1523157

Creswell, J. W., \& Creswell, J. D. (2017). Research design: Qualitative, quantitative, and mixed methods approaches. Sage publications.

Crilly, N. (2019). Creativity and fixation in the real world: A literature review of case study research. Design Studies, 64, $154-168$ https://doi.org/https://doi.org/10.1016/j.destud.2019.0 7.002

Cuff, D. (1992). Architecture: The story of practice. Mit Press.

Daalhuizen, J., Timmer, R., Van Der Welie, M., \& Gardien, P. (2019). An architecture of design doing: A framework for capturing the ever-evolving practice of design to drive organizational learning. International Journal of Design, 13(1), 37-52.

De Leeuw, E. D. (2008). Choosing the method of data collection.

Diggle, P. J., Chetwynd, A. G., \& Chetwynd, A. (2011). Statistics and scientific method: an introduction for 
students and researchers. Oxford University Press.

Feijs, L., \& Toeters, M. (2018a). Cellular automata-based generative design of pied-de-poule patterns using emergent behavior: Case study of how fashion pieces can help to understand modern complexity. International Journal of Design, 12(3), 127-144.

Feijs, L., \& Toeters, M. (2018b). Cellular automata-based generative design of Pied-de-poule patterns using emergent behavior: Case study of how fashion pieces can help to understand modern complexity. International Journal of Design, 12(3), 127-144.

Ferguson, S. M., Olewnik, A. T., \& Cormier, P. (2014). A review of mass customization across marketing, engineering and distribution domains toward development of a process framework. Research in Engineering Design, 25(1), 11-30.

Findeli, A., Brouillet, D., Martin, S., Moineau, C., \& Tarrago, R. (2008). Research through design and transdisciplinarity: A tentative contribution to the methodology of design research. Focused--Current Design Research Projects and Methods. Swiss Design Network Symposium, 67-91.

Fink, A. S. (2000). The role of the researcher in the qualitative research process. A potential barrier to archiving qualitative data. Forum Qualitative Sozialforschung/Forum: Qualitative Social Research, 1(3).

Franceschini, F., \& Maisano, D. (2019). Design decisions: concordance of designers and effects of the Arrow's theorem on the collective preference ranking. Research in Engineering Design, 30(3), 425-434. https://doi.org/10.1007/s00163-019-00313-9

Frayling, C. (1994). Research in art and design (Royal College of Art Research Papers, vol 1, no 1, 1993/4).

Garcia, J. J., Pettersen, S. S., Rehn, C. F., Erikstad, S. O., Brett, P. O., \& Asbjørnslett, B. E. (2019). Overspecified vessel design solutions in multistakeholder design problems. Research in Engineering Design, 30(4), 473-487. https://doi.org/10.1007/s00163-019-00319-3

Genç, Ç., Buruk, O. T., Yılmaz, S. İ., Can, K., \& Özcan, O. (2018). Exploring computational materials for fashion: Recommendations for designing fashionable wearables. International Journal of Design, 12(3), 119.

Glass, R. L. (1995). A structure-based critique of contemporary computing research. The Journal of Systems and Software, 28(1), 3-7. https://doi.org/10.1016/0164-1212(94)00077-Z

Goodwin, C. (2000). Practices of seeing, visual analysis: An ethnomethodological approach. Handbook of Visual Analysis, 157, 182.

Goucher-Lambert, K., \& Cagan, J. (2019). Crowdsourcing inspiration: Using crowd generated inspirational stimuli to support designer ideation. Design Studies, 61, 1-29. https://doi.org/10.1016/j.destud.2019.01.001

Graeff, E., Maranzana, N., \& Aoussat, A. (2019). Biomimetics, where are the biologists? Journal of Engineering Design, 30(8-9), 289-310. https://doi.org/10.1080/09544828.2019.1642462

Gralla, E. L., Herrmann, J. W., \& Morency, M. (2019). Design problem decomposition: an empirical study of small teams of facility designers. Research in Engineering Design, 30(2), 161-185. https://doi.org/10.1007/s00163-018-0300-0

Gyory, J. T., Cagan, J., \& Kotovsky, K. (2019). Are you better off alone? Mitigating the underperformance of engineering teams during conceptual design through adaptive process management. Research in Engineering Design, 30(1), 85-102. https://doi.org/10.1007/s00163-018-00303-3

Han, J., Forbes, H., \& Schaefer, D. (2021). An exploration of how creativity, functionality, and aesthetics are related in design. Research in Engineering Design, 1-19.

Han, X., Li, R., Wang, J., Ding, G., \& Qin, S. (2020). A systematic literature review of product platform design under uncertainty. Journal of Engineering Design, 31(5), 266-296.

Hanrahan, B. V., Yuan, C. W., Rosson, M. B., Beck, J., \& Carroll, J. M. (2019). Materializing interactions with paper prototyping: A case study of designing social, collaborative systems with older adults. Design Studies, 64, 1-26. https://doi.org/10.1016/j.destud.2019.06.002

Herr, C. M. (2015). Action Research as a Research Method in Architecture and Design. Proceedings of the 59th Annual Meeting of the ISSS-2015 Berlin, Germany, 1(1).

Herrera Batista, M. Á. (2010). Investigación y diseño: reflexiones y consideraciones con respecto al estado de la investigación actual en diseño. No Solo Usabilidad, 9.

Hobye, M., \& Fagerberg Ranten, M. (2019). Behavioral complexity as a computational material strategy. International Journal of Design, 13(2), 39-53.

Hyysalo, S., Marttila, T., Perikangas, S., \& Auvinen, K. (2019a). Codesign for transitions governance: A Midrange pathway creation toolset for accelerating sociotechnical change. Design Studies, 63, 181-203.

Hyysalo, S., Marttila, T., Perikangas, S., \& Auvinen, K. (2019b). Codesign for transitions governance: A midrange pathway creation toolset for accelerating sociotechnical change. Design Studies, 63, 181-203. https://doi.org/10.1016/j.destud.2019.05.002

Jagtap, S. (2019). Design and poverty: a review of contexts, roles of poor people, and methods. Research in Engineering Design, 30(1), 41-62. https://doi.org/10.1007/s00163-018-0294-7

Joost, G., Bredies, K., Christensen, M., Conradi, F., \& Unteidig, A. (2016). Design as research: Positions, arguments, perspectives. Birkhäuser.

Jørgensen, U. (2001). Grounded theory: Methodology and theory construction. International Encyclopedia of the Social \\& Behavioral Sciences, 1, 6396-6399.

Kennedy-Clark, S. (2013). Research by Design: DesignBased Research and the Higher Degree Research student. Journal of Learning Design, 6(2), 26-32.

Keyson, D. V, \& Bruns, M. (2009). Empirical research through design. Proceedings of the 3rd IASDR Conference on Design Research, 4548-4557.

Khalaj, J., \& Pedgley, O. (2019). A semantic discontinuity detection (SDD) method for comparing designers' product expressions with users' product impressions. Design Studies, 62, 36-67. https://doi.org/10.1016/j.destud.2019.02.002

Kitchenham, B. (2004). Procedures for performing systematic reviews. Keele, UK, Keele University, 33(2004), 1-26.

Koskinen, I., Zimmerman, J., Binder, T., Redstrom, J., \& 
Wensveen, S. (2011). Design research through practice: From the lab, field, and showroom. Elsevier.

Kothari, C. R. (2004). Research methodology: Methods and techniques. New Age International.

Li, Q., \& Luximon, Y. (2018). Understanding older adults' post-adoption usage behavior and perceptions of mobile technology. International Journal of Design, 12(3), 93-110.

Li, Y., Shieh, M.-D., \& Yang, C.-C. (2019). A posterior preference articulation approach to Kansei engineering system for product form design. Research in Engineering Design, 30(1), 3-19.

Martinec, T., Škec, S., Horvat, N., \& Štorga, M. (2019). A state-transition model of team conceptual design activity. Research in Engineering Design, 30(1), 103132. https://doi.org/10.1007/s00163-018-00305-1

Mathias, D., Snider, C., Hicks, B., \& Ranscombe, C. (2019). Accelerating product prototyping through hybrid methods: Coupling 3D printing and LEGO. Design Studies, 62, 68-99. https://doi.org/10.1016/j.destud.2019.04.003

McDonald, J. K., \& Michela, E. (2019). The design critique and the moral goods of studio pedagogy. Design Studies, 62, 1-35. https://doi.org/10.1016/j.destud.2019.02.001

McKinnon, H., \& Sade, G. (2019). Exploring the home environment: fusing rubbish and design to encourage participant agency and self-reflection. Design Studies, 63 , 155-180. https://doi.org/10.1016/j.destud.2019.05.001

Morkos, B., Joshi, S., \& Summers, J. D. (2019). Investigating the impact of requirements elicitation and evolution on course performance in a pre-capstone design course. Journal of Engineering Design, 30(4-5), 155-179.

Motta-Filho, M. A. (2021). Brand experience manual: bridging the gap between brand strategy and customer experience. Review of Managerial Science, 15(5), $1173-1204$

Nielsen, J., \& Molich, R. (1990). Heuristic evaluation of user interfaces. Proceedings of the SIGCHI Conference on Human Factors in Computing Systems, 249-256.

Ozer, M., \& Cebeci, U. (2019). Affective design using big data within the context of online shopping. Journal of Engineering Design, 30(8-9), 368-384. https://doi.org/10.1080/09544828.2019.1656803

Pakkanen, J., Juuti, T., \& Lehtonen, T. (2019). Identifying and addressing challenges in the engineering design of modular systems - case studies in the manufacturing industry. Journal of Engineering Design, 30(1), 32-61. https://doi.org/10.1080/09544828.2018.1552779

Paluck, E. L., \& Cialdini, R. B. (2014). Field research methods. Handbook of Research Methods in Social and Personality Psychology, 81-97.

Park-Lee, S., \& Person, O. (2018). Briefng beyond documentation: An interview study on industrial design consulting practices in Finland. International Journal of Design, 12(3), 73-91.

Park, D., Han, J., \& Childs, P. R. N. (2021). 266 Fuzzy frontend studies: current state and future directions for new product development. Research in Engineering Design, $1-33$.

Pedgley, O., Şener, B., Lilley, D., \& Bridgens, B. (2018). Embracing material surface imperfections in product design. International Journal of Design, 12(3), 21-33.
Perez-Gomez, A. (1999). Hermeneutics as discourse in design. Design Issues, 15(2), 71-79.

Pessôa, M. V. P., \& Becker, J. M. J. (2020). Smart design engineering: a literature review of the impact of the 4th industrial revolution on product design and development. Research in Engineering Design, 31(2), 175-195.

Piccolo, S. A., Maier, A. M., Lehmann, S., \& McMahon, C. A. (2019). Iterations as the result of social and technical factors: empirical evidence from a large-scale design project. Research in Engineering Design, 30(2), 251270. https://doi.org/10.1007/s00163-018-0301-z

Randolph, M. F. (2003). Science and empiricism in pile foundation design. Géotechnique, 53(10), 847-875.

Read, H. (1948). Education through art.

Redström, J. (2017). Making design theory. MIT Press.

Reimlinger, B., Lohmeyer, Q., Moryson, R., \& Meboldt, M. (2019). A comparison of how novice and experienced design engineers benefit from design guidelines. Design Studies, 63, 204-223. https://doi.org/10.1016/j.destud.2019.04.004

Renzi, C., Leali, F., \& Di Angelo, L. (2017). A review on decision-making methods in engineering design for the automotive industry. Journal of Engineering Design, 28(2), 118-143.

Rodgers, P. A., \& Milton, A. (2013). Research methods for product design.

Roesler, A., Grigg, E. B., Martin, L. D., Ross, F. J., Feil, M., Rampersad, S. E., Haberkern, C. M., \& Martin, L. D. (2019). Practice-centered design of an anesthesia medication template to reduce medication handling errors in the operating room. International Journal of Design, 13(1), 53-68.

Roy, R., \& Warren, J. P. (2019). Card-based design tools: a review and analysis of 155 card decks for designers and designing. Design Studies, 63, 125-154. https://doi.org/10.1016/j.destud.2019.04.002

Saliminamin, S., Becattini, N., \& Cascini, G. (2019a). Sources of creativity stimulation for designing the next generation of technical systems: correlations with R\&D designers' performance. Research in Engineering Design, 30(1), 133-153. https://doi.org/10.1007/s00163-018-0299-2

Saliminamin, S., Becattini, N., \& Cascini, G. (2019b). Sources of creativity stimulation for designing the next generation of technical systems: correlations with R\&amp;D designers' performance. Research in Engineering Design, 30(1), 133-153. https://doi.org/10.1007/s00163-018-0299-2

Santolaya, J. L., Lacasa, E., Biedermann, A., \& Muñoz, N. (2019). A practical methodology to project the design of more sustainable products in the production stage. Research in Engineering Design, 30(4), 539-558. https://doi.org/10.1007/s00163-019-00320-w

Saravanan, A., \& Jerald, J. (2019). Ontological model-based optimal determination of geometric tolerances in an assembly using the hybridised neural network and Genetic algorithm. Journal of Engineering Design, 30(4-5), $180-198$. https://doi.org/10.1080/09544828.2019.1605585

Schröppel, T., Miehling, J., \& Wartzack, S. (2021). The role of product development in the battle against productrelated stigma--a literature review. Journal of Engineering Design, 32(5), 247-270. 
Self, J. A. (2019). Communication through design sketches: implications for stakeholder interpretation during concept design. Design Studies, 63, 1-36. https://doi.org/10.1016/j.destud.2019.02.003

Selvefors, A., Marx, C., Karlsson, M. A. I. C., \& Rahe, U. (2018). (How) can appliances be designed to support less energy-intensive use? Insights from a field study on kitchen appliances. International Journal of Design, 12(3), 35-55.

Simon, H. A. (1996). The science of design: creating the artificial.

Solomon, M. (2007). Social empiricism. MIT press.

Stigliano, A. (1989). Hermeneutical practice. Saybrook Review, 7(2), 47-67.

Stringer, E. T. (2008). Action research in education. Pearson Prentice Hall Upper Saddle River, NJ.

Sung, E., Kelley, T. R., \& Han, J. (2019). Influence of sketching instruction on elementary students' design cognition: a study of three sketching approaches. Journal of Engineering Design, 30(6), 199-226. https://doi.org/10.1080/09544828.2019.1617413

Swann, C. (2002). Action research and the practice of design. Design Issues, 18(1), 49-61.

Takahashi, I., Oki, M., Bourreau, B., Kitahara, I., \& Suzuki, K. (2018). An empathic design approach to an augmented gymnasium in a special needs school setting. International Journal of Design, 12(3), 111125.

Tempczyk, H. (1986). A survey of research and studies on design. Design Studies, 7(4), 199-215.

Thiese, M. S. (2014). Observational and interventional study design types; an overview. Biochemia Medica, 24(2), 199-210.

Tsai, W. C., \& Hoven, E. Van Den. (2018). Memory probes: Exploring retrospective user experience through traces of use on cherished objects. International Journal of Design, 12(3), 57-72.

Valverde, N., Ribeiro, A. M. R., Henriques, E., \& Fontul, M. (2019). An engineering perspective on the quality of the automotive push-buttons' haptic feedback in optimal and suboptimal interactions. Journal of Engineering Design, 30(8-9), 336-367. https://doi.org/10.1080/09544828.2019.1656802

Van der Linden, V., Dong, H., \& Heylighen, A. (2019a). Populating architectural design: Introducing scenariobased design in residential care projects. International Journal of Design, 13(1), 21-36.

Van der Linden, V., Dong, H., \& Heylighen, A. (2019b). Tracing architects' fragile knowing about users in the socio-material environment of design practice. Design Studies, 63(1), 65-91. https://doi.org/10.1016/j.destud.2019.02.004

Vasantha, G. V. A., Roy, R., Lelah, A., \& Brissaud, D. (2012). A review of product--service systems design methodologies. Journal of Engineering Design, 23(9), 635-659.

Vaughan, L. (2017). Practice-based design research. Bloomsbury Publishing.

Vegt, N., Visch, V., Vermeeren, A., De Ridder, H., \& Hayde, Z. (2019). Balancing game rules for improving creative output of group brainstorms. International Journal of Design, 13(1), 1-19.

Wasson, C. (2000). Ethnography in the field of design. Human Organization, 377-388.
Wilson, A. (2015). A guide to phenomenological research Nursing Standard (2014+), 29(34), 38.

Wlazlak, P., Eriksson, Y., Johansson, G., \& Ahlin, P. (2019). Visual representations for communication in geographically distributed new product development projects. Journal of Engineering Design, 30(8-9), 385403. https://doi.org/10.1080/09544828.2019.1661362

Wood, A. E., \& Mattson, C. A. (2019). Quantifying the effects of various factors on the utility of design ethnography in the developing world. Research in Engineering Design, 30(3), 317-338. https://doi.org/10.1007/s00163-018-00304-2

Yin, R. K. (2003). Case study research: design and methods (ed.). Applied Social Research Methods Series, 5.

Zhang, X., \& Thomson, V. (2019). Modelling the development of complex products using a knowledge perspective. Research in Engineering Design, 30(2), 203-226. https://doi.org/10.1007/s00163-017-0274-3 